Acknowledgements: Grant GV2016/140. Conselleria Educació Ciencia i esports. Valencia, Spain.

Disclosure of Interest: None declared

DOI: 10.1136/annrheumdis-2017-eular.3433

\section{AB0930 CROSS-SECTIONAL ANALYSIS OF THE AUTONOMIC NERVOUS SYSTEM (HEART RATE VARIABILITY): CORRELATIONS WITH PSYCHOLOGICAL DIMENSIONS IN WOMEN WITH FIBROMIALGIA, RHEUMATOID ARTHRITIS AND HEALTHY CONTROLS}

T.L. Santiago, D. Peixoto, C. Costa, J.A. Pereira da Silva. Rheumatology, Centro Hospitalar e Universitário de Coimbra, Coimbra, Portugal

Background: Autonomic nervous system (ANS) dysfunction has been proposed to play a role in the pathophysiology and maintenance of rheumatic diseases, including fibromyalgia (FM) and rheumatoid arthritis (RA). Heart rate variability (HRV) analyses provide a quantitative marker of ANS activity. Some studies suggest an association between reduced HRV parameters and psychological dimensions, namely a negative emotional state. This led us to hypothesize an association between rheumatic diseases and higher sympathetic activity mediated by a negative emotional state.

Objectives: To establish correlates between HRV parameters with rheumatic disease groups and psychological dimensions.

Methods: Sixty women (FM, $n=20$; RA, $n=20$; healthy controls (Ct), $n=20$ ) completed a self-reported questionnaire addressing demographic characteristics, the Eysenck Personality Questionnaire, the Hospital Anxiety and Depression Scale, and the Beck Depression Inventory-II (BDI-II).

HRV analysis was performed by photopletismography between 8:00 and 10:00am, after an overnight fast, in a sitting position, for 5-minutes. We obtained the time and frequency-domain indices of HRV, including SDNN (standard deviation of the NN intervals), RMSSD (root-mean square differences of successive R-R intervals), high frequency power (HF), low frequency power (LF) and very low frequency (VLF). LF/HF ratio reflects sympathetic to parasympathetic balance. Statistical analysis were performed considering: A) Rheumatic disease groups (FM/RA/Ct), and B) Psychological scores (irrespective of disease group): higher versus lower tertile in the personality questionnaires and score above (depression) versus below 20, in BDI-II. Between-groups comparisons were performed with Kruskal-Wallis test and analysis of covariance (age was adjusted during analyses), as appropriate.

Results: Neuroticism, anxiety and depression scores were significantly higher in FM and RA patients compared with controls $(p<0.05)$. However, no statistically significant difference was observed in HRV parameters between disease groups. No statistically significant difference was observed in HRV parameters between tertile groups for psychological dimensions, except for depression. The values of $\mathrm{HF}$ power (parasympathetic activity) were lower in the high depression group compared to the low depression group $(p<0.05)$. The ratio of $L F / H F$ was higher among the depression group than the control group $(p<0.05)$.

Conclusions: This study did not found significant differences in the HRV between the three rheumatic disease groups. The results confirm that depression is accompanied by dysfunction of the autonomic nervous system, specifically lower parasympathetic activity. These results suggest that psychological dimensions, namely depression, must be taken into account when evaluating the ANS and its impact in disease pathogenesis.

Disclosure of Interest: None declared

DOI: 10.1136/annrheumdis-2017-eular.5974

\section{AB0931 EFFECTS OF MANUAL THERAPY ON PAIN, POSTURE, FLEXIBILITY, QUALITY OF SLEEP AND DEPRESSIVE SYMPTOMS IN FIBROMYALGIA SYNDROME}

T. Duymaz ${ }^{1}$, G. Sakınç Toprak ${ }^{2}{ }^{1}$ Physiotherapy and Rehabilitation, Istanbul Bilim University, Şişli-Istanbil; ${ }^{2}$ Physiotherapy and Rehabilitation, Acıbadem Hospital, Izmit-Kocaeli, Turkey
Background: Fibromyalgia syndrome (FMS) is a chronic musculoskeletal pain condition characterized by widespread and a constellation of other symptoms. Objectives: The purpose of this study was to investigate the therapeutic effects of a Manual Therapy (MT) protocol for improving pain, posture, flexibility, tender points, impact of FMS symptoms, sleep quality and depressive symptoms with FMS.

Methods: Patients completed demographic information, a number of self-report measures including Visual Analog Scale for assessing pain, Fibromyalgia Impact Questionnaire, the Pittsburgh Quality of Sleep Questionnaire Index and the Hospital of Anxiety and Depression Scale.The patients underwent a protocol of MT for a 60 -minute session for 3 weeks (5/wk). The protocol was as the following release and mobilisation. All analyses were performed with the SPSS (version 22.0)statistical program

Results: 16 women,3 men patients who had FMS were treated with MT.Demographic variables of the participants are provided in Table 1. While there was a favorable change in all measurement parameters after treatment $(p<0.001)$. There was a statistically significant difference between before and after the treatment measurement parameters (Table 2)

Table 1.Demographic variables of the participants

\begin{tabular}{lc}
\hline Variables & Mean \pm SD $(\min -\max )$ \\
\hline Age $($ year) & $36.05 \pm 8.16(20-58)$ \\
BMl $\left(\mathrm{kg} / \mathrm{m}^{2}\right)$ & $24.19 \pm 4.16(19.49-33.06)$ \\
Duration of symptoms (year) & $4.81 \pm 2.41(1-9)$ \\
\hline
\end{tabular}

Conclusions: This study found that the application of a MT protocol was effective for improving pain, posture, flexibility,tender points, impact of FMS symptoms, sleep quality and depressive symptoms in individuals with FMS.

References:

[1] Goldenberg DL, Burckhardt C, Crofford L. Management of fibromyalgia syndrome. JAMA. 2004;292:2388-2395.

[2] Castro-Sa' nchez AM, Matara' n-Peñ arrocha GA, Arroyo-Morales M. Effects of myofascial release techniques on pain, physical function, and postural stability in patients with fibromyalgia: a randomized controlled trial. Clin Rehabil. $2011 ; 25: 800-813$

Disclosure of Interest: None declared

DOI: 10.1136/annrheumdis-2017-eular.5833

\section{AB0932 PREVALENCE OF TYPE D PERSONALITY IN TURKISH PATIENTS WITH FIBROMYALGIA SYNDROME}

Y. Garip ${ }^{1}$, T. Guler ${ }^{1}$, O.B. Tuncer ${ }^{2}$, S. Onen ${ }^{3} .{ }^{1}$ Physical Medicine and Rehabilitation, Ankara Numune Training and Research Hospital, Ankara; ${ }^{2}$ Physical Medicine and Rehabilitation, Medipol University Medical School, Istanbul; ${ }^{3}$ Psychiatry, Sevket Yılmaz Eğitim ve Araştırma Hastanesi, Bursa, Turkey

Background: Type D personality is a distressed personality type involving two personality traits, namely negative affectivity and social inhibition, which are described as tendency to experience negative emotions and to inhibit self-expression in social relationships, respectively (1).

Objectives: The present study investigated the prevalence of type $D$ personality in Turkish patients with fibromyalgia (FM) and evaluated the association between type D personality and clinical parameters of FM. Although there is adequate number of studies focusing on the relation between FM and psychological conditions such as depression and anxiety; this topic has been rarely addressed in the literature.

Methods: A total of 100 patients with FM fulfilling 1990 American College of Rheumatology (ACR) diagnostic criteria and 50 healthy controls were included. Type D personality was assessed by Type D Scale-14 (DS-14). FM disease severity was determined by Fibromyalgia Impact Questionnaire (FIQ), functional status by Stanford Health Assessment Questionnaire (HAQ), and health-related quality of life (HRQoL) by Nottingham Health Profile (NHP). Severity of pain and fatigue were measured by Visual Analog Scale (VAS).

Abstract AB0931 - Table 2. Comparison of before and after treatment in all measurement parameters

\begin{tabular}{|c|c|c|c|c|}
\hline Variables & $\begin{array}{c}\text { Before Treatment } \\
\text { Mean } \pm \text { SD (min-max) }\end{array}$ & $\begin{array}{c}\text { After Treatment } \\
\text { Mean } \pm \text { SD (min-max) }\end{array}$ & $\mathrm{z}$ & $\mathrm{p}$ \\
\hline Number of tender points & $12.10 \pm 1.24(10-15)$ & $7.31 \pm 2.26(2-11)$ & -3.840 & $0.000^{* *}$ \\
\hline VAS at night & $6.84 \pm 1.30(3-9)$ & $0.91 \pm 0.64(0-2)$ & -3.843 & $0.000^{\star \star}$ \\
\hline VAS in activity & $7.31 \pm 1.24(4-9)$ & $1.11 \pm 0.81(0-2.20)$ & -3.850 & $0.000^{\star *}$ \\
\hline VAS in rest & $6.42 \pm 1.46(3-9)$ & $0.49 \pm 0.81(0-2.40)$ & -3.834 & $0.000^{\star *}$ \\
\hline Distance of Tragus-Wall $(\mathrm{cm})$ & $12.08 \pm 1.95(9-17)$ & $10.72 \pm 1.90(8.20-15.60)$ & -3.529 & $0.000^{* \star}$ \\
\hline Distance of processus spinosus-Skapula $(\mathrm{cm})(\mathrm{R})$ & $10.65 \pm 3.03(6.50-17)$ & $10.26 \pm 2.76(7-15)$ & -2.007 & $0.045^{\star}$ \\
\hline Distance of processus spinosus-Skapula $(\mathrm{cm})(\mathrm{L})$ & $11.21 \pm 3.17(7-17)$ & $10.26 \pm 2.76(7-15)$ & -2.842 & $0.004^{\star \star}$ \\
\hline Trunk Lateral Flexion $\left({ }^{\circ}\right)(\mathrm{R})$ & $36.47 \pm 3.35(30-41)$ & $37.00 \pm 3.39(30-41)$ & -1.821 & 0.069 \\
\hline Trunk Lateral Flexion $\left({ }^{\circ}\right)(\mathrm{L})$ & $33.47 \pm 4.01(27-41)$ & $36.68 \pm 3.28(30-41)$ & -3.534 & $0.000^{\star \star}$ \\
\hline Distance of hand-floor $(\mathrm{cm})$ & $6.86 \pm 4.84(0-17)$ & $5.18 \pm 3.92(0-14)$ & -3.219 & $0.001^{\star \star}$ \\
\hline $\mathrm{FIQ}$ & $56.25 \pm 18.74(19.79-85.58)$ & $46.39 \pm 17.99(19.59-67.98)$ & -3.724 & $0.000^{\star \star}$ \\
\hline HAD-A & $10.89 \pm 3.91(5-19)$ & $4.73 \pm 3.49(0-10)$ & -3.849 & $0.000^{\star *}$ \\
\hline HAD-D & $9.78 \pm 3.29(2-15)$ & $5.05 \pm 2.06(0-9)$ & -3.632 & $0.000^{\star \star}$ \\
\hline PSQI & $10.52 \pm 3.40(5-15)$ & $3.63 \pm 2.47(0-8)$ & -3.830 & $0.000^{\star \star}$ \\
\hline
\end{tabular}

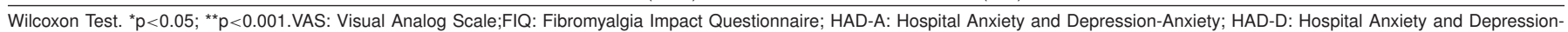
Depression; PSQI: Pittsburgh Quality of Sleep Questionnaire Index. 
Results: Prevalence of type D personality was $33 \%$ in FM patients, and $12 \%$ in controls. It was higher in the patients with $\mathrm{FM}$ (Odds ratio $(\mathrm{OR})=3.612$ confidence interval $(\mathrm{Cl}) 95 \%(1.398-9.333))(p<0.01)$ compared with controls. Type D FM patients scored higher in tender point count (TPC), FIQ, HAQ, VAS-pain and all NHP subgroups except energy $(p<0.01)$ (Table 1). Type $D$ personality was found as correlated with FIQ, TPC, HAQ, VAS-pain and NHP subgroups except energy $(p<0.01)$.

Table 1. The comparison of clinical variables and HRQoL between type $D$ and non-type $D$ patients

\begin{tabular}{lccc}
\hline & $\begin{array}{c}\text { Type D FM patients }(n=33) \\
\text { mean } \pm \text { standard deviation }\end{array}$ & $\begin{array}{c}\text { Non-type D FM patients }(n=67) \\
\text { mean } \pm \text { standard deviation }\end{array}$ & $p$ value \\
\hline Pain $($ VAS, $10 \mathrm{~cm})$ & $8.55 \pm 0.75$ & $5.80 \pm 1.19$ & $<0.00001^{*}$ \\
Fatigue $($ VAS $10 \mathrm{~cm})$ & $4.45 \pm 3.18$ & $4.01 \pm 3.54$ & 0.549 \\
TPC & $15.72 \pm 2.33$ & $12.91 \pm 1.84$ & $<0.00001^{*}$ \\
FIQ & $86.27 \pm 8.43$ & $64.07 \pm 11.47$ & $<0.00001^{*}$ \\
HAQ & $1.24 \pm 0.80$ & $0.52 \pm 0.51$ & $<0.00001^{*}$ \\
NHP-pain & $89.1 \pm 10.73$ & $64.33 \pm 14.07$ & $<0.00001^{*}$ \\
NHP-physical mobility & $53.41 \pm 16.91$ & $22.57 \pm 21.01$ & $<0.00001^{*}$ \\
NHP-energy & $45.45 \pm 42.13$ & $37.31 \pm 41.14$ & 0.358 \\
NHP-sleep & $80.00 \pm 19.36$ & $56.23 \pm 22.55$ & $<0.00001^{*}$ \\
NHP-social isolation & $60.60 \pm 37.24$ & $15.52 \pm 25.06$ & $<0.00001^{*}$ \\
NHP-emotional reactions & $83.71 \pm 14.14$ & $51.52 \pm 25.06$ & $<0.00001^{*}$
\end{tabular}

HRQoL: Health-related quality of life, FM: Fibromyalgia, VAS: Visual analog scale, TPC: Tender point count, FIQ: Fibromyalgia Impact Questionnaire, HAQ: Stanford Health Assessment Questionnaire, NHP: Nottingham Health Profile. ${ }^{*} \mathrm{p}<0.01$ (significant).

Conclusions: Type D personality is prevalent among Turkish patients with FM, with a rate of $33 \%$. It is associated with poor HRQoL regarding pain, physical mobility, sleep, and social and emotional functions. Based on our findings, assessment of personality characteristics of the patients with FM may hold the key for the treatment of the disease. Presence of type $D$ personality should be taken into account in FM in order to develop new treatment strategies for the patients who have inadequate response to conventional therapies.

References:

[1] Denollet J. Type D personality: a potential risk factor refined. J Psychosom Res 2000;49:255-66.

Disclosure of Interest: None declared

DOI: 10.1136/annrheumdis-2017-eular.1547

\section{Back pain, mechanical musculoskeletal problems, local soft tissue disorders}

\section{AB0933 PREDICTIVE MODEL FOR SHOULDER PAIN USING CLINICAL AND EPIDEMIOLOGICAL VARIABLES}

C. Feced Olmos ${ }^{1}$, E. Labrador Sánchez ${ }^{1}$, J. Ivorra Cortes ${ }^{1}$, E. Grau Garcia ${ }^{1}$, E. Vicens Bernabeu ${ }^{1}$, J.J. Fragio Gil ${ }^{1}$, R. González Mazarío ${ }^{1}$, C. Alcañiz Escandell ${ }^{1}$, I. Cánovas Olmos ${ }^{1}$, I. Chalmeta Verdejo ${ }^{1}$, L. Gonzalez Puig ${ }^{1}$ I. Martínez Cordellat ${ }^{1}$, C. Nájera Herranz ${ }^{1}$, R. Negueroles Albuixech ${ }^{1}$, J.E. Oller Rodriguez ${ }^{1}$, F.M. Ortiz-Sanjuan ${ }^{1}$, D. Hervás Marín ${ }^{2}$, J.A. Román Ivorra ${ }^{1,3}$. ${ }^{1}$ Rheumatology Department, HUP la Fe; ${ }^{2}$ Biostatistics Unit, IIS la Fe $;{ }^{3}$ Medical School, UCV, Valencia, Spain

Background: Shoulder pain is a very common complaint with poor prognosis and high recurrence. To evaluate the shoulder pain, anamnesis and physical examination are used, but a diagnosis of certainty is difficult. Clinical history and specific exploration maneuvers tend to be poorly correlated with the underlying problem. There are few studies that assess the predictability of shoulder pathology using patient characteristics and exploration.

Objectives: To assess if the combination of exploratory maneuvers and clinical data predicts the type of affection of the painful shoulder in a sensitive and specific way.

Methods: We conducted a prospective study with patients who attended to the Rheumatology Department of HUP La Fe by painful shoulder between February 2016 and January 2017, excluding those with known inflammatory diseases. A rheumatologist performed the anamnesis and the selected exploratory maneuvers: Jobe and Gerber test and palpation of the acromioclavicular joint. A second rheumatologist, blind to physical examination and medical history, performed the shoulder ultrasound scan. Biostatistic analysis was performed using software $\mathrm{R}$ version 3.3.2.

Results: 119 patients $(66.4 \%$ women) with a mean age of $60 \pm 12.56$ years and shoulder pain were collected. Time of pain evolution was $20.43 \pm 24.09$ months and the right shoulder was the most affected one (71.4\%). The association between the maneuvers of Jobe and the involvement of the supraspinatus (SE), as well as the Gerber maneuver with the affectation of the subscapular were statistically significant. However the sensitivity and specificity of both maneuvers are very low, so that alone is not suitable to identify the affected tendon or the type of alteration. Thus, a predictor model (nomogram) of the most common shoulder pathologies (subacromiodeltoid bursitis, tendinosis or SE tears) was developed using epidemiological and clinical examination variables.

Conclusions: Based on our results, the predictor model performed using epidemiological and clinical examination variables would be able to predict the most frequent pathologies of the shoulder. Imaging tests have a certain delay time, and by applying this predictor model, a diagnosis of presumption could be established in primary care, giving the opportunity to institute an early treatment. In addition, patients could be referred more efficiently to the appropriate specialty (rheumatology, traumatology or rehabilitation), avoiding delays.

Disclosure of Interest: None declared

DOI: 10.1136/annrheumdis-2017-eular.6010

\section{AB0934 TREATMENT OF LATERAL EPICONDYLITIS WITH ESWT: A SHAM-CONTROLLED DOUBLE BLINDED RANDOMISED STUDY}

E.A. Gokmen ${ }^{1}$, O. Karatas ${ }^{2}$, E. Gilgil ${ }^{3}{ }^{1}$ Physical Medicine and Rehabilitation, Antalya Training and Research Hospital; ${ }^{2}$ Physical Medicine and Rehabilitation, Korkuteli Public Hospital; ${ }^{3}$ Physical Medicine and Rehabilitation, Akdeniz University Hospital, Antalya, Turkey

Background: Lateral epicondylitis is a term describing the clinical condition that causes pain and sensitivity in musculotendinous adhesion sites of the wrist extensor muscles originating from the lateral epicondyle of the humerus, resulting in repetitive stresses due to overuse $(1,2)$.

Objectives: The aim of this study was to investigate the efficiency of extracorporeal shockwave therapy (ESWT) in the treatment of lateral epicondylitis as randomized, prospective, controlled and double blind.

Methods: 47 patients ( 35 women, 12 men) with lateral epicondylitis were included in the study. The mean age of patients was $45.94 \pm 10.46$ years. Patients were randomized into two groups: active ESWT $(n=22)$ and sham ESWT $(n=25)$. Patients were randomly allocated to receive 1 session per week for 3 weeks of either sham or active ESWT.

Patients were evaluated before the treatment, and at the end of the first week, first month and third month after the last treatment session with Patient-rated Tennis Elbow Evaluation Questionnaire (PRTEE), Visual Analogue Scale (VAS) for pain assessment and physical examination of lateral epicondyle of the elbow with special clinical tests.

Results: Compared with pretreatment values in ESWT group, significant improvement was observed in all parameters after treatment. At the first week after the therapy significant improvement was observed in sham group but at the first and third month after the therapy no significant difference was found. In comparison of ESWT and sham over 3 months after the treatment, significant improvements were observed in ESWT group in all parameters.

Conclusions: there was a significant decrease in pain and a significant improvement in function following ESWT. Although there was a reduction in pain and improvement in function with sham treatment as well, this difference was not as significant as in active group.

References:

[1] Murrey PM, Ön Kol ve Dirsek. In: Weinstein SL, Buckwalter JA, Alpaslan M (Ç. Ed). Turek Ortopedi Ilkeler ve Uygulamaları. Ankara, Güneş 2009; 401-15.

[2] Cordasco FA, Parkes JC II. Overuse Injuries of the Elbow. In: Nicholas JA, Hershman EB. The Upper Extremity In Sports Medicine. Missouri, Mosby-Year Book 1995: 317-30.

Disclosure of Interest: None declared

DOI: 10.1136/annrheumdis-2017-eular.6508

\section{AB0935 THE ROLE OF EPIDURAL INJECTIONS IN PATIENTS WITH CHRONIC SCIATICA: A REVIEW BASED ON THE EVIDENCE OVER THE PAST 5 YEARS}

G. Ferreira Dos Santos, M. Amaral Silva, E. Marques, M. De Fátima Carvalho. Physical and Rehabilitation Medicine Department, Hospital de Curry Cabral Centro Hospitalar de Lisboa Central (CHLC), Lisbon, Portugal

Background: Among various modalities applied in the management of painful conditions of the spine, epidural injections (EI) are one of the most commonly utilized interventions. El can be administered in the lumbar spine by either caudal (CEI), interlaminar (IEI), or transforaminal (TEI) approaches and various steroids have been used in these injections ${ }^{(1,2)}$. The purpose of $\mathrm{El}$ is to provide analgesia for a varying duration, whilst making it easier for the patient to undergo a rehabilitation program during this time ${ }^{(1)}$

Objectives: The aim of this review is to evaluate the efficacy of the different types of El in patients suffering from chronic sciatica, based on the evidence published over the past 5 years.

Methods: Relevant studies were retrieved by searching PubMed, Medline, The Cochrane Library and UpToDate. Publications from 2012 to 2016 which specified the use of El to treat chronic sciatica were considered, and all the studies selected were written in the English language only.

A total of 11 articles were gathered, of which 5 were excluded after analysis of their title and abstract. Of the 6 papers included in this study, 5 are systematic reviews and 1 is a meta-analysis of 10 randomized controlled trials.

The outcomes measured were improvement in pain and functional status. The Numeric Rating Scale (NRS) and Visual Analogue Scale (VAS) were the most commonly used baseline scales for pain evaluation. The Oswestry Disability Index (ODI) was the most used scale for the functional disability scoring system in the literature. 